\title{
Serebral Parezide Gözlemsel Yürüme Analizinin Yeri ve Kullanılabilirliği
}

\section{Usage and Importance of Observational Gait Analysis In Cerebral Palsy}

\section{N. Ekin AKALAN ${ }^{1}$ Yener TEMELLI'}

${ }^{1} \dot{I}$ stanbul Üniversitesi, Sağllk Bilimleri Fakültesi, Fizyoterapi ve Rehabilitasyon Bölümü, İstanbul, Türkiye

${ }^{2}$ Ístanbul Üniversitesi, Istanbul Tıp Fakültesi, Ortopedi ve Travmatoloji Anabilim Dall, Ístanbul, Türkiye

Yazışma Adresi

Correspondence

N. Ekin AKALAN Istanbul Üniversitesi Sağllk Bilimleri Fakültesi Ebelik Bölümü, Demirkapı Cad. Karabal Sok. Bakırköy Ruh ve Sinir Hastalıkları Hastanesi Bahçesi içi, 34740, Bakırköy/İstanbul ekin.akalan@gmail.com Tel: 0 (212) 4141500

Geliş Tarihi/Received 29.05.2014

Kabul Tarihi/Accepted 23.06.2014

HSP 2014;1(1):28-45

\section{Özet}

Yürüme karmaşık hareketler sinsilesi olduğundan klinikte anliz edilmesi güçtür. Serebral Palsili çocuklarda pek çok çeşit yürüme problemi görülür. Klinikte serebral palsili'li çocukların değişik yürüme problemlerini inceleyecek tatmin edici güvenilirliğe sahip bir yürüme değerlendirme aracı bulunmamaktadır. Bu derlemenin amac1, spastik hemiparezi ve diparezili çocuklarda video bazlı gözlemsel yürüme analizinin güvenilirliğinin nasıl değerlendirilmesi gerektiği ve bu değerlendime aracının günümüzdeki durumuyla klinikte kullanılamaya uygun olup olmadığını tartışmak, limitasyonlarını incelemektir. Karşılaştırma ve detaylı derleme sonuçlarına göre günümüzde video bazlı gözlemsel yürüme analizi metotları orta seviyede gözlemciler arası güvenilirliğe ve orta-ileri düzeyde gözlemci içi güvenilirliğe sahip olduğunu ortaya koymuştur. Sonuç olarak gözlemci içi güvenilirlik video bazlı gözlemsel yürüme analizinin klinikte kullanılabileceğini, ancak gözlemciler arası güvnilirliğin yükseltilmesi için çalışılması gerektiği ortaya konmuştur.

Anahtar kelimeler: Fizyoterapi, güvenilirlik, klinik değerlendirme, serebral palsi, yürüme analizi

\begin{abstract}
Gait is a complex sequence of movements so that it is very hard to analyze in clinic. Children with cerebral palsy have lots of different type of gait abnormalities. There is no clinically satisfied and reliable gait assessment tool for analyzing gait problem in cerebral palsy. The purpose of the review was to determine the reliability of clinically available video based observational gait analysis on children with spastic hemiplegics and diplegics and to investigate how they can be used in clinical practice as a standard examination tool. The review results showed that clinically available methods have moderate level reliability for between rater reliability and moderate to advance level reliability for within rater reliability. This review suggested that between rater reliability is high enough to use it in clinical practice but within rater reliability needs to be improved by the feature studies.
\end{abstract}

Key Words: Physiotherapy, reliability, clinical practice, cerebral palsy, gait analysis 


\section{Giriş}

Günlük yaşantıda en sık kullanılan aktivitedir ve aktivite seviyesine bağlı olsa da, ortalama bir insan günde 5.000-15.000 yılda 2-5 milyon adım atar. ${ }^{1}$ Bundan 10 y1l önceye göre yürüme sıklığımız \%25 azalsa da, 265 erkek ve 228 kadının 35 ve 74 yaşlarındaki ortalama günlük yürüyüşünü inceleyen bir çalışmada, günlük adım sayısının erkeklerde 11,900'dan 6700'e ve kadınların 9300'den 7300'e düştüğü görülmüştür. ${ }^{2}$

İnsan gözü ne kadar ehilde olsa yürümenin hızlı gerçekleşen hareketlerini aynı anda tüm eklem hareketleri için inceleyebilecek kadar yetenekli değildir. Standart klinik değerlendirme metotlarıyla karmaşık yürüme bozukluklarının başarılı bir şekilde belirlenememekte ve kaydedilememektedir. Yürüme analizi, yürümeye ait gerek görüntüsel (kinematik) gerekse harcanan güç ve enerji ile ilgili (kinetik) kesin ve güvenilir bilgi sağladığından yeni tedavi tekniklerinin geliştirilmesinde, bunların diğer tedavi metotları ile karşılaştırılmasında ve böylece hastaların daha yeni ve onlar için en uygun tedavi programı ile iyileştirilmesinde de etkili olmaktadır. ${ }^{2,3}$

İlk yürüme resimleri, Edwin Smith'in cerrahi papürüslerinde (MÖ 4000) vardır. Aristo (MÖ 384-322) insan ve hayvan yürüyüşlerini karşılaştırmıştır. Galileo (1564-1642), Borelli, (1680), Leizig (1836), Weber kardeşler (1855), Marey (1872), Carlet (1845-1892) Mubridge (1904), gibi birçok araştırmacının yürüme analizi konulu çalışmaları bulunur. Bilgisayar oyunları endüstrisindeki ilerlemeler sayesinde karmaşı matematik model ve simülasyonlar yürüme analizini daha detaylı incelenebilir hale getirmiştir. Jacklin Perry, David Sutherland, Gordon Rose, James R. Gage bilgisayarlı yürüme analizini ilk gerçekleştirenlerdendir. ${ }^{3,4}$

Klinikte kullanılan gözlemsel yürüme analiz yöntemleri, klinikte kullanılabilecek düzeyde yüksek güvenilirliğe sahip bir analiz yöntemi oluşturulmasına olanak vermek ve gelecekte bu konuda çalışacak bilim insanlarına önem vermeleri gereken bölümlerin altını çizmek amacıyla çeşitli başlıklar altında derlenmiştir. Derleme kronoljik bir sıralama yerine bu başlilar üzerinden şekillendirilmiştir.

\section{Klinikte Kullanılan Yürüme Değerlendirme Sistemleri}

Klinikte kullanılan yürüme değerlendirme sistemleri iki kategoriye ayrılabilir; bunlardan ilki ambulasyon profilleri olarak bilinir, zaman-mesafe parametreleri ve yürüme yetenekleri hakkındaki bilgileri içerirler. ${ }^{5}$ Diğeri ise Günlük yaşam aktiviteleri (GYA) sistemleri olarak bilinir ve kinematik-eklem açısı ve zaman-mesafe parametrelerini değerlendirirler. ${ }^{5}$ 


\section{Ambulasyon Profilleri}

Ambulasyon profilleri hastanın yürümesini değerlendirme tekniği, lokomotor yeteneğin klinik incelenmesi ${ }^{7}$ veya yürüme işlevinin niceliksel bir değerlendirme metodu olarak tanımlanabilir. Ambulasyon profilleri çeşitli spesifik hasta grupları için kullanılmıştır (örneğin serebral parezi, ${ }^{6}$ şiddetli ve orta derecede nörolojik problemi olan hastalar, ${ }^{7}$ ampute olan vakalar ${ }^{8}$ veya daha genel kullanım için ${ }^{5}$ ).

Bazı profiller her biri siralı bir skala ile derecelendirilen bir seri test sonunda ortaya çıkan olgu performansını global skor toplamı olarak belirlemişlerdir. Buna karşılık diğerleri olguların performansını zaman ve mesafe gibi değişkenlerle aralıklı skorlama metodları ile belirlemişlerdir. $^{7}$

Reimes Serebral Palsili (SP) çocukların oturma, yürüme, merdiven çıkma gibi aktivitelerine ait performanslarını global skor toplamına dayanan bir ambulasyon profili ile değerlendirmiştir. ${ }^{6}$ Skorlama, çocukların aktiviteleri yaparken aldıkları yardımın miktarına göre yapılmıştır. Yürüme yeteneği yürürken aldıkları yardıma, yürüyebildikleri mesafeye ve yürümedeki bozukluklara göre değerlendirilmiştir. Ancak ambulasyon profilinin güvenilirliği ve geçerliliği hakkında veri içeren herhangi bir rapor yayımlanmamıştır. ${ }^{6}$

Bir başka ambulatuvar değerlendirme sistemide, değişik yüzeylerde yürüme için gerekli olan zaman ve yardım miktarını temel alan fonksiyonel bir skorlama metodu olarak geliştirilmiştir. ${ }^{4,6} \mathrm{Bu}$ metod değerlendirme formu ambulasyon için alınacak yardım miktarına göre sekiz ambulasyon durumundan oluşmuştur. Ambulayon profili en az yardım ihtiyacından (yardımsız=1) en çok yardım ihtiyacına (kısa bacak cihazı ve yarı yürüteç=8) doğru sıralanmıştı. Hastalar beş değişik yüzeyde (yerde, asfalt zeminde, halıda, engelli zeminde ve merdivenlerde) yürüyüşleri sırasındaki aldıkları mesafe ölçülmüştür. Bu yüzeyler en kolaydan (yer=0.1) en zora (merdiven=0.5) doğru sıralanmış, ambulatuar seviyedeki hastaların, herbir bölümü tamamlayabilmesi için ihtiyaç duyduğu zaman kaydedilmiştir ve sonrada beş bölümün her biri için uygun bir ondalık sayıyla çarpılmıştır. $\mathrm{Bu}$ sayılar toplanmış ve ambulatuar durumuna göre belirlenen sayılarla çarpılmıştır. Sonuç fonksiyonel skoru vermiştir. Düşük toplam skor hastanın bir veya birkaç yürüme bölümünü tamamlaması için gereken sürenin kısalığını göstermektedir. Bu değerlendirme metodu özellikle yardımcı yürüme cihazı kullanan hastaların ilerlemelerinin nicel olarak dökümante edilmesini sağlamış ve hastaların eski işlerine devam etmeleri veya yeni iş için eğitilmelerindeki rehabilitasyon programında gerekli tavsiyelerin verilmesinde etkili olmuştur. $\mathrm{Bu}$ sisteme ait ne bir güvenilirlik nede geçerlilik çalışması yapılmıştır. ${ }^{6}$ 
Ambulasyon profilinin güvenilirliği Nelson, Olney ve arkadaşları tarafından 1974 ve 1979 yılları arasında geliştirilmiştir. ${ }^{7,8}$ Nelsonun fonksiyonel ambulasyon profili (FAP) olguların ayakta durma dengesinden, bağımsız ambulasyonuna kadar tüm aktivitelerini değerlendirmiştir. On-onbeş dakika içinde tamamlanabilen bu profil, bölümlerin değerlendirilebilmesi için gereken zamanın da kaydedilmesine olanak sağlamıştır. Sadece bir kronometre ve bir paralel barla uygulanan bu profil, üç kısımdan oluşmuştur. İlk olarak statik faz; her iki ayak üzerinde ayakta durmaktan etkilenmemiş taraf üzerinde ve sonrada etkilenmiş taraf üzerinde ayakta durmayı (maximum 60 saniye ) içermiştir. İkinci olarak dinamik faz; ağırlık aktarma fazı ve bir ekstremiteden diğerine hızlı bir şekilde ağırlı̆̆ aktarmayı içermiştir. Üçüncü faz; etkili ambulasyon fazı olarak da bilinir, paralel bar boyunca (6m) yürümeyi, yardımcı cihazla yürümeyi ve mümkün olduğunda altı metrenin üzerinde bağımsız yürümeyi içermiştir. FAP’nin gözlemci içi ve gözlemciler arası güvenilirliği, nörolojik problemi olan 31 hastada ölçülmüştür. Gözlemci içi güvenilirlik bir gözlemcinin bir saatlik aralıklarla 31 olguyu bir günde değerlendirmeye alması ve gözlemciler arası güvenilirlik ise iki hafta sonra aynı değerlendirmeyi tekrar yapması şeklinde düzenlenmiştir. Güvenilirlik düzeyi Pearson korolasyon metodu ile belirlenmiştir. Tüm korolasyonlar 0.89'dan büyük bulunmuş ve gözlemciler arası güvenilirlik için bulunan etkileşme de bu sonuca eşlik etmiştir ( $r=0.91-0.99)$. Bu nedenle Nelson'un FAP'i değişik gözlemciler görevlendirilse bile zaman içinde yüksek güvenilirlikle tekrarlanabilme özelliğine sahiptir. ${ }^{7}$

Olney ve arkadaşları, ampute olan hastalar için ondört bölümlü bir ambulasyon profili geliştirmişlerdir. $\mathrm{Bu}$ profil temel yürüme yeteneği (7 bölüm), serbest hızda yürüme karakteristiği (3 bölüm), yürüme için efor (3 bölüm) ve yürüme dayanıklılığı (1 bölüm) bölümlerinden oluşmuştur. Temel yetenek bölümü Nelson'nun altı bölümüne bir yeni bölüm (merdiven çıkma) eklenmesi ile oluşturulmuştur. Serbest yürüme hızı karakteristikleri için, hız, birim zamanda atılan adım sayısı ve adım uzunluğu ölçülmüştür. Yürüme eforu için ise yürümeye ait değerlendirme yapıldıktan sonra ve dinlenirken nabız sayılmıştır. Ayrıca bu verilerden yaşa uygun maksimum kalp hızına ait yüzdeler elde edilmiştir. Yürüme dayanıklılığı; hastanın kendini rahatsız hissedinceye kadar veya onbeş dakika geçinceye kadar aldığı mesafe hesaplanarak belirlenmiştir. Gözlemciler arası güvenilirlik için iki terapist yirmialtı normal olguyu testlemiştir. Pearson korolasyonu bir bölüm hariç (yardımla yürüme sırasında hızın tayini; $r=0.79$ ) tüm bölümler için 0.90'ın üzerinde bulunmuştur (range 0.900.99). Elli dokuz ampute hastaya aynı uygulama yapıldıktan sonra, gerek eski sonuçların karsılaştırmasında, gerekse bilinen stantardlar içinde ilerlemeyi değerlendirmede en değerli ambulasyon profili olduğu kanıtlanmıştır. ${ }^{8}$ 
Yukarda yazilan ambulasyon profilleri arasinda Nelson ve Olney tarafindan geliştirilenler uzun dönemdeki değişikliklerin değerlendirilmesi için en uygun olanlarıdır. Bunun iki nedeni vardır. Birincisi, sıralı skaladan ziyade oran skalası kullanmasını önermeleridir ki buda onlara tüm iyileşme dönemi boyunca daha duyarlı bir veri toplama yeteneği kazandırmıştır. İkincisi, zaman, hız veya nabız gibi değişkinler toplu veri tabanları olarak kullanılabilicekleri gibi herbir değişken bireysel olarak da incelenebilir ve bilinen standartlarla karşılaştırılabilir. ${ }^{7,8}$ Bunun yanında Reimes'in ${ }^{6}$ ve Wolfson'un ${ }^{9}$ geliştirdikleri ambulasyon profilleri ise fonksiyonel izleme araçları ile performans düzeyini ve bağımsızlığa ait skorları derecelendirebilmektedir.

\section{Gözlemsel Yürüme Analizi}

Gözlemsel yürüme analizi (GYA), yürümeyi nicel olarak tarif eder ve klinisyenlerce sıkça kullanılır. Gözlemsel olarak değerlendirilen hastaların yürümelerine ait bozukluklarını belirler. ${ }^{3}$ GYA ile yürüme bozuklarının gözlemcinin kararına dayanan tespiti ve bu bozuklukların derecesi belirlenebilmektedir. ${ }^{10}$ Yürümenin gözlemsel değerlendirmesi birçok klinisyen tarafından nerdeyse günlük rutine oturtulduysa da, uluslararası kullanılan standardize edilmiş bir gözlemsel yürüme analizi sistemi bulunmamaktadır. ${ }^{4,10,11}$ Spesifik ve sistematik yürüme değerlendirme ve skorlama formları geliştirilirken, klinisyenler genel olarak daha bireysel yaklaşımlarda bulunmuşlardır. Gözlemsel yürüme analizi klinisyenlere; kolay, çabuk ve bilgisayarlı yürüme analizi sistemlerine kıyasla ucuz olmasıyla cazip gelmiştir.

İlk GYA sistemi Kaliforniyadaki Rancho Los Amigos Tip Merkezindeki Fizik Tedavi ve Patokinezyoloji Servisi tarafından oluşturulmuştur. Bu sistem çok detaylı hazırlanmış olması nedeniyle dünyada en yaygın kullanılan GYA sistemi olmuştur. ${ }^{3}$ GYA sisteminin kullanıcıları, normal yürüme paterninin ve eklem hereketlerinin mental imajını geliştirmek zorunda olmalarından dolayı, bu sistemde ilk olarak normal insan yürüyüşü hakkında bilgi verilmiştir (ayak bileği, diz, kalça, pelvis'in hareket açıklığı (sadece sagital plan ROM), kas aktivitesi, tork ve fonksiyonel anlam). Bu değişkenler bir kitap içinde tarif edilmiş ve her segment yürüme siklüsünün her altfazı için ayrı ayrı gösterilmiştir (ilk temas, yüklenme fazı, basma fazı ortası, basma fazı sonu, salınım öncesi faz, salınımın başlama fazı, salınım fazı ortası, salınım fazı sonu). Kullanıcılara normal yürüme paterni öğretildikten sonra patolojilerin, normal yürümede oluşan deviyasyonlar olarak farkedilmesi sağlanmıştır. Daha sonra Gözlemcinin tüm vücudu içeren bu yürüme analizi formunu doldurması istenmiştir. $\mathrm{Bu}$ form yürümeye ait deviyasyonların bir kontrol listesi şeklinde düzenlenmiştir. $\mathrm{Bu}$ formda 
sıralar yürüme deviyasyonlarını, kolonlar ise yürüme fazlarını temsil etmektedir. Değerlendirmeyi daha kolay bir hale getirmek için, form majör (boş kutular) ve minör (gri renkli kutular) yürüme deviyasyonları içeren fazları birbirinden ayrılmıştır. İlgili faza ait uygulanamayacak deviyasyonlar siyah kutularla gösterilmektedir. Perry en başarılı gözlemsel yürüme analizinin ancak iki kademede yapılabileceğini belirtmiştir. İlk olarak hareketlerin akışının genel olarak hissedilmesi, sonrada anatomik sıra içinde ayaktan başlayarak yukarı doğru hareketin izlenilmesi gerektiğini vurgulamıştır. Bu sıralı hareket dizisi farklı eklemlerdeki değişik olayların fark edilmesini kolaylaştırmıştır. Her bir vücut bölümünün hareketi, o bölümün normal hareketleri ve bunların formda tanımlanmış deviasyonları ile karşılaştırılmıştır. Perry ayak bileği, diz ve kalça eklemlerinin değerlendirilmesinin iyi öğrenilmesi gerektiğini belirtmiştir. Ayrıca gözlemcinin yürüme analizi formu boyunca horizantal olarak aynı anatomik bölgeyi izlemesini tavsiye etmektedir. Bulgular, her bir yürüme alt fazına ait deviasyonlar toplanarak bir toplam bacak fonksiyonu halinde yorumlanmaktadır. Rhancho Los Amigos'un GYA sistemi hasta için uygun tedavi planının çizilmesinde de oldukça yararlı olmuştur. Ancak bu sistem yıllardır kullanılmasına rağmen Rancho Los Amigos GYA sistemine ait bir güvenilirlik veya geçerlilik çalışması rapor edilmemiştir. $^{3}$

Diğer yürüme deviyasyon analiz sistemleri özellikle bireysel hastalık sınıflarına ait yürüme anormalliklerine yönelmiştir. Örneğin romotoid artrit ${ }^{5}$, hemipleji ${ }^{5}$ veya alt ekstremite amputasyonları gibi spesifik hastalıklara ait veya Stanik ve ark. tarafından tanımlanan Ljubljana Rehabilitasyon Merkezinin kliniksel yürüme analizi gibi daha genel kullanımlı sistemler yayınlanmıştır. Diğerleri ise var olan değerlendirme formlarından uyarlanmıştır. ${ }^{12-14}$ Daha sonra bu formlara fiziksel değerlendirme bulguları ve tedavi amaçları bölümlerinin eklenmesiyle, yürüme deviyasyonlarının giderilmesi için yapılacak girişimlere karar verilmesi ve tedavi planının çizilmesi daha kolay bir hale gelmiştir. ${ }^{5}$

GYA’nın güvenilirliği ve geçerliliği üzerine yapılmış az sayıda çalışma vardır (Tablo 1). Her bir çalışmada değişik metodolojik yaklaşımlar kullanılsa da, sonuçlar genel olarak orta derecede bir güvenilirlik seviyesi göstermektedir. Bu çalışmalarda bir çok bölümün birbirlerine benzer sonuçlar vermesi GYA'nin klinikte kullanılan güvenilir bir metod olması için çok erken olduğunun sinyallerini vermektedir. Çalışmaların çoğunda gözlemcilerin eğitimi, skorlama metodu, veri birikimi ve istatiksel analiz konularında birçok soru işareti bulunmaktadır. $^{5}$ 
Tablo 1. GYA’nın güvenilirliği ve geçerliliği üzerine yapılımış çalışma listesi

\begin{tabular}{|c|c|c|c|c|c|c|}
\hline Çalışma & $\begin{array}{l}\text { Çalışma } \\
\text { Grubu }\end{array}$ & Gözle mci & $\begin{array}{l}\text { Skorlama } \\
\text { Biçimi }\end{array}$ & $\begin{array}{l}\text { Veri } \\
\text { Biçimi }\end{array}$ & $\begin{array}{l}\text { İstatiksel } \\
\text { Analiz }\end{array}$ & $\begin{array}{l}\text { Çalışma } \\
\text { Tipi }\end{array}$ \\
\hline $\begin{array}{l}\text { Goodkin ve } \\
\text { Diller (1973) }\end{array}$ & $\begin{array}{l}\text { Hemipleji } \\
\mathrm{N}=10\end{array}$ & $\begin{array}{l}\text { Fzt. } \\
N=3\end{array}$ & $\begin{array}{l}\text { Ordinal } 3 \\
\text { nokta skalası }\end{array}$ & Canlı & Yüzde uyumu & Gü \\
\hline $\begin{array}{l}\text { De Brune } \\
(1982)\end{array}$ & $\begin{array}{l}\text { Cerebral } \\
\text { palsy } \\
\mathrm{N}=18\end{array}$ & $\begin{array}{l}\text { Ort. as. } \\
\mathrm{N}=6\end{array}$ & $\begin{array}{l}\text { Ordinal } 3 \\
\text { nokta skalası }\end{array}$ & Video & Yok & Gü \\
\hline $\begin{array}{l}\text { Miyazaki ve } \\
\text { Kubota } \\
(1984)\end{array}$ & $\begin{array}{l}\text { Hemipleji } \\
\mathrm{N}=48\end{array}$ & $\begin{array}{l}\text { Karışık } \\
\mathrm{N}=5\end{array}$ & $\begin{array}{l}\text { Ordinal } 4 \\
\text { nokta skalası }\end{array}$ & Canl1 & $\begin{array}{l}\text { Pearson } \\
\text { Korolasyon }\end{array}$ & $\begin{array}{l}\text { Gü } \\
\mathrm{Ge}\end{array}$ \\
\hline $\begin{array}{l}\text { Saleh ve } \\
\text { Murdoch } \\
(1985)\end{array}$ & $\begin{array}{l}\text { Ampute } \\
\mathrm{N}=5\end{array}$ & $\begin{array}{l}\text { Karışı1k } \\
\mathrm{N}=4\end{array}$ & Nominal & Canlı & Yüzde uyumu & $\mathrm{Ge}$ \\
\hline $\begin{array}{l}\text { Krebs ve } \\
\text { arkadaşları } \\
(1985)\end{array}$ & $\begin{array}{l}\text { Bilateral } \\
\text { KAFO } \\
\mathrm{N}=15\end{array}$ & $\begin{array}{l}\mathrm{Fzt} \\
\mathrm{N}=3\end{array}$ & $\begin{array}{l}\text { Ordinal } 3 \\
\text { nokta skalası }\end{array}$ & Video & $\begin{array}{l}\text { Yüzde uyumu } \\
\text { SHÖ } \\
\text { SKK }\end{array}$ & $\begin{array}{l}\text { Gü } \\
\text { Ge }\end{array}$ \\
\hline $\begin{array}{l}\text { Patla ve } \\
\text { Clouse } \\
(1988)\end{array}$ & $\begin{array}{l}\text { Hetorojen } \\
\mathrm{N}=8\end{array}$ & $\begin{array}{l}\text { Kin.öğ. } \\
\mathrm{N}=5\end{array}$ & Nominal & Video & $\begin{array}{l}\text { Doğru/ Doğru } \\
\text { olmayan }\end{array}$ & Gü \\
\hline $\begin{array}{l}\text { Eastlock ve } \\
\text { ark. (1991) }\end{array}$ & $\begin{array}{l}\mathrm{RA} \\
\mathrm{N}=3\end{array}$ & $\begin{array}{l}\text { Fzt } \\
N=54\end{array}$ & $\begin{array}{l}\text { Ordinal } 3 \\
\text { nokta skalası }\end{array}$ & Video & $\begin{array}{l}\text { Kappa ve } \\
\text { SKK }\end{array}$ & Gü \\
\hline $\begin{array}{l}\text { Akalan ve } \\
\text { ark. (1999) }\end{array}$ & $\begin{array}{l}\mathrm{SP} \\
\mathrm{N}: 41\end{array}$ & $\begin{array}{l}\text { Fzt } \\
N=3\end{array}$ & $\begin{array}{l}\text { Ordinal } 3 \\
\text { nokta skalası }\end{array}$ & Vido & $\begin{array}{l}\text { Kappa ve } \\
\text { Yüzde tut }\end{array}$ & Gü \\
\hline $\begin{array}{l}\text { Maathuis ve } \\
\text { ark. (2005) }\end{array}$ & $\mathrm{N}=24$ & $\begin{array}{l}\mathrm{Fzt} \\
\mathrm{N}=3\end{array}$ & $\begin{array}{l}\text { Ordinal } 5 \\
\text { nokta skalası }\end{array}$ & Video & Kappa & Gü \\
\hline
\end{tabular}

Fzt: Fizyoterapist; Gü: Güvenilirlik; Ge: Geçerlilik; Ort. As.: Ortopedi asistanlarl; KAFO: Diz-ayakbileği- ayak ortezi; SHÖ: Standart hata ölçümü; SKK: Sinıflar arası korolasyon koefisyon; Kin Ö̆ğ: Kinezyoloji öğrencileri; RA: Romatoid Artit.

Yukarıda belirtildiği gibi yürüme değişkenlerinin seçimi en sık olarak hasta tipine ve metodolojik şartlara bağlı olarak yapılmıştır. Değişkenlerin seçiminde düşünülmesi gereken bir diğer konuda GYA'nın uluslararası kullanımda bir standarda oturtulmasıdır. Örneğin ister enstrumental (bilgisayarlı) ister gözlemsel teknikle olsun yürüme kapasitesini en iyi temsil eden değişkenlerin, yürüme deviasyonlarının düzeltilmesi için yapılan tedavinin etkisini en iyi belirten verilerin, klinikte anlamlı olarak gösterilmesi oldukça önemlidir.

\section{Bulgu, Sonuç ve Tartışma}

\section{Değişkenlerin Seçilmesi}

GYA sistemlerinin güvenilirlik sistemleri hakkında yapılan az sayıda çalışmada seçilme nedeni, sistemin tipi ve seçilen değişkenlerin sayısı konularında farklılıklar bulunmaktadır. Örneğin Goodkin ve Diller ${ }^{14}$ NewYork Medical School Orthotic Gait Analysis çalışma 
formlarını, 10 hemiplejik çocuğun yürümelerini değerlendirmek için kullanmışlardır. $\mathrm{Bu}$ form on yedi tane yürüme deviasyonundan oluşan bir liste içermişti; üç gövde deviasyonu (lateral, posterior, ve anterior gövde eğilimi), iki diz deviyasyonu (aşırı diz bükülmesi, diz hiperekstansionu), beş kalça deviasyonu (kalça abduksiyon, adduksiyon, rotasyon, yükselme ve oraklama) ve diğerleri (yetersiz itme, aşırı lateral-medial ayak kontağı, ayak parmağının yere sürtmesi, eşit olmayan adım uzunluğu, voulting, kol salınımı ve baş kontrolü). Buna karşılık Eastlack ve ark. ${ }^{17}$ video kayıtlı GYA’nin gözlemci içi ve gözlemciler arası güvenilirlik derecesini üç romatoid artritli hasta üzerinde değerlendirmiştir. $\mathrm{Bu}$ değerlendirmede gözlemciler beş diz deviyasyonuna konsantre edilmiştir (ilk temas, orta basma, topuk kalkışı, parmak ucu kalkışı fazlarında diz fleksionu ve genuvalgum). Ayrıca beş zaman-mesafe değişkeni değerlendirilmiştir (adım ve çift adım uzunluğu, basma zamanı, birim zamanda atılan adım sayısı ve adım açıklığı).

Yürüme değişkenlerinin seçimi hastalığın tipine göre de yapılmıştır. Örnek olarak Saleh ve Murdock ${ }^{20}$ ampute hastaların basma ve salınım alt fazları için ayak-ayak bileği ve diz hareketerini ve bunun yanında prostetik bacağa ait adım uzunluğu ve adımlama zamanını değerlenmiştir. Bundan başka Bruin ve ark. ${ }^{13}$ Serebral Palsili çocuklarda lordoz, trandelenburg yürüyüşü, diz hareketleri, ayak kontağı ve ardışık ekstremite harekerleri gibi bir kaç değişkeni değerlendirmiştir. Sadece basma fazını ${ }^{10}$ veya tüm yürüme siklüsünü içine alan $^{11,16}$ ve ayaktan kalçaya yürüme deviasyonlarının değerlendirilmesine olanak sağlayan sadece iki çalışma bulunmaktadır.

Akalan ve arkadaşlarının ${ }^{4} 41$ serebral palsili katılımcının serbest hızda yürüyüşleri standart bir protokolle sadece basma fazı için değerlendirilmek üzere videoya kaydedilmiş ve bu çocukların yürüme değerlendirmesi deneyimli gözlemciler ile incelenmiştir.

Yürüme deviyasyonları değerlendirilirken sadece basma fazı ile sınırlanmasının nedeni, öne hareket için basma döneminin önemi ve gözlemcilerin hem basma hem de salınım dönemlerini birlikte değerlendirdiklerinde güvenilirliğin düşmesidir. ${ }^{10,16}$ Son olarak Miyazaki ve Kubota ${ }^{19}$ kendilerine özel bir değişken kombinasyonu kullanmışlardır; Akıcılık, simetri, desteklenebilirlik, değişkenlik, şok, itme, bastona bağımlılık ve ayak kontağı. Bu çalışma sekiz değişkenin, topuk ve ayağın maruz kaldığı kuvveti ölçen cihazların gösterdiği sekiz dalga formunu karşılaştırmak amacıyla yapılmıştır.

$\mathrm{Bu}$ konudan en son yapılan güvenilirlik çalışması olan Edinburg Gözlemsel Yürüme Analiz sisteminde yan ve ön-arka görüntülerinden hem basma hem de salınım fazının ayak, diz, kalça ve gövde hareketleri izlenmesini ve 5 nokta skalası ile değerlendirilmesini istemiştir. ${ }^{11} \mathrm{Bu}$ çalışmada sadece serebral palsili vakalar katılımcı olmuştur ve gözlemcilerden 
transvers plan problemleri bile sagital planda değerlendirilmesi istenmiştir. $\mathrm{Bu}$ durumda gözlemciler arası güvenilirliği azaltan bir metod olmuştur. ${ }^{11}$

Gövde deviasyonu ile birlikte ayaktan kalçaya birden fazla plandaki yürüme deviasyonu bu çalışmada yer almıştır. ${ }^{10,11,14,16}$ En son olarak eksternal destek kullanımı ve bastona bağımlılık ile ayak itişi skorlanmıştır.

\section{Standardizasyon}

Standardizasyon, yürüyüşün değerlendirilmesi için istenilen bir özellik olmuştur. Çünkü gözlemcilerden normal yürüyüş için baştan ayağa tüm vücudun üç boyutlu hareketini bilmeleri ve bu hareketlerin hasta yürüşü ile karşılaştırmaları beklenmiştir. Bu da eğitimle ve zamanla gelişebilecek bir beceri olmuştur. Devameden çalışmalar ve metodun sıkça uygulanımı ile yürürme analizi bir sanat haline dönüşmektedir. ${ }^{15} \mathrm{Bu}$ yüzden çalışmadan önce gözlemciler için bir eğitim programı hazırlanmalı ve gözlemcilerin önceki tecrübeleride bu programa dahil edilmelidir. Skorlama metodu ile ilgili ikinci önemli özellik, gözlemcilerin, varolan yürüme deviasyonlarının basit tanımlarına (nominal ölçüm) vaya deviasyonun derecelendirilmesine (ordinal ölçüm) ihtiyaç duymalarıdır. Gerek canlı yürüme, gerekse videobanttan izlenen yürüme sırasında yapılan değerlendirme metodları gözlemcilerin kararını etkileyecektir, bu sebeple standardize edilmelidir. ${ }^{5}$ Standardizasyon konusunun en çok önem verildiği iki çalışmada ${ }^{4,10}$, kameraların lokasyonundan (kameranın yerden ve yürüme yoluna uzaklığı), yürüme yolunun boyutları ve lokasyona, detaylarıyla verilmiş ve bu konuda yapılan çalışmalara temel oluşturacak bilgiler verilmiştir.

\section{3. Örneklem Büyüklüğü}

Güvenilirlik çalışmaları için bir başka önemli konuda örnek büyüklüğüdür. Tablo 1 de görülen çalışmalarda örnek büyüklüğü oldukça geniş bir dizi oluşturmaktadır ( $n=3$ 'den 48'e). Örnekler genellikle hemiparezili ${ }^{14}$, Serebral Palsi' ${ }^{4}{ }^{4,13}$, alt ekstremite sakatlığı bulunan ve diz ayak-ayakbileği ortazi (KAFO) kullanması gereken ${ }^{10}$ veya romotoid artrit' $1 i^{17}$ hastalar gibi homojen gruplardan oluşurlar. Sadece bir çalışmada ampute, serebral palsy gibi olguların birlikte olduğu heterojen bir olgu grubu kullanılmıştır. ${ }^{16} 54$ gözlemcinin kullanıldığı bir çalışma dışında ${ }^{17}$ diğer birçok çalışmada gözlemci sayısı 3 ile 6 arasında değişmektedir. Bu çalışmada 54 gözlemci 3 romatoit artritli hastanın yürüyüşünü değerlendirmiştir: Fazla sayıda gözlemci ve az sayıda olgu kullanmışlardır. 


\section{Geçerlilik}

Gözlemcilerden beklenen, dikkatlice düzenlenen geçerlilik çalışmaları ile detaylı olarak donatılmış bilgisayarlı yürüme analizi metodları kadar başarılı olmaları ve vizüel analizin güvenilirliğini sürdürebilecek bir saptama seviyesine de sahip olmalarıdır.

Son geçerlilik çalışması, vizüel değerlendirmeyi, bir objektif ölçüm cihazının kliniksel kullanımının geçerliliğini saptaması için düzenlendiğinden diğerleri ile farklılık gösterir. ${ }^{19}$ Aslında yazarlar gözlemsel değerlendirme ile (4 gözlemci ile) klinikte, vertikal yer reaksiyon kuvvetini ölçmek için kullanılan bir cihazın geçerliliğini göstererek aradaki ilişkiyi karşılaştırmaya yönelik bir çalışma yapmışlardır. Kesişimsel geçerlilik ile ilgili çalışmaları düzenlerken karşılaşılan problemlerden biride, gözlemcilerin, bilgisayarlı yürüme tekniğinin doğruluğunda yükselme gösterme çabalarının, gözlemsel yürüme analizinin güvenilirliğini ölçmek için gösterdikleri çabadan daha fazla olmasıdır. Bu nedenle kriter-ilişkili GYA' ne ait açık bir çalışma bulunmamaktadır.

Gözlemciler arasındaki tutarlılık seviyesi birçok çalışmada gösterilmesine rağmen sadece iki çalışmada GYA sistemlerinin gözlemci içi güvenilirliği ${ }^{10,13}$ ve üç çalışmada geçerliliği konusuna değinilmiştir. ${ }^{16,19,20}$ Gözlemci içi güvenilirlik çalışmalarında gözlemciler 1 hafta veya 1 aylık aralıklarla aynı yürüme kayıtlarını değerlendirmişlerdir. Değerlendirmeler arası geçen zaman oldukça önemlidir. Aslında bu zaman aralığı gözlemcilerin ilk değerlendirmede verdikleri skorları unutacakları kadar uzun olmalıdır. Eğer aynı seansta fazla sayıda olgu skorlanıyorsa bir haftalık aralıklarla değerlendirme yeterli olabilir. Gözlemcilerde oluşabilecek önyargıyı gidermenin bir başka yolu da olguların değerlendirme sırasını rastgele bir biçimde değiştirmektir. ${ }^{10}$

Yapılan yürüme çalışmalarından bazıları diğerlerine göre daha güvenilir sonuçlar bulmuşlardır. Bu çalışmalarda basma döneminin salınım dönemine göre daha değişken olduğu gösterilmiştir. ${ }^{4,10,17}$ GYA çalışmaları karşılaştırıldığında, ilerleticili video analiz yöntemi ile yürüme deviyasyonlarının saptanma kapasitesinin yükseltilebileceği sonucu çıkmaktadır.

\section{Yöntem Değerlendirmesi}

Tüm güvenilirlik çalışmalarında değerlendirilen yöntemin, çalışmada en kritik bölüm olduğu bilinir. Bu çalışmalarda aynı gözlemciler arasında veya gözlemcilerin test tekrarı gibi standardizasyon gerektiren konulara ilişkin kıstas oluşturacak kararlar alınması gerekmektedir. Yürüyüşün değerlendirilmesi için standardizasyon, istenilen bir özelliktir çünkü gözlemcilerden normal olguların yürüyüş için baştan ayağa tüm vücudun üç boyutlu hareketini bilmeleri ve bu hareketlerin hasta yürüyüşü ile karşılaştırmaları beklenmektedir. Bu 
da eğitimle ve zamanla gelişebilecek bir beceridir. ${ }^{3}$ Devam eden alıştırmalara ve metodun sıkça uygulanımı ile yürüme analizi bir sanat haline dönüşür. ${ }^{15} \mathrm{Bu}$ yüzden çalışmadan önce gözlemciler için bir eğitim programı hazırlanmalı ve gözlemcilerin önceki tecrübeleri de bu programa dâhil edilmelidir. Skorlama metodu ile ilgili ikinci önemli özellik, gözlemcilerin, var olan yürüme deviasyonlarının basit tanımlarına (nominal ölçüm) veya deviasyonun derecelendirilmesine (ordinal ölçüm) ihtiyaç duymamalarıdır. Gerek canlı yürüme gerekse videobanttan izlenen yürüme sırasında yapılan değerlendirme metodları gözlemcilerin kararını etkileyecektir bu sebeple standardize edilmelidir. ${ }^{4,10}$

\section{Gözlemci Eğitimi}

Yapılan GYA güvenilirlik çalışmalarında gözlemci eğitimi ve tecrübeleri konularında herhangi bir standart olmadığını görmekteyiz. Gözlemciler genel olarak fizyoterapistler, ortopedi asistanları, fizyoterapi öğrencileri, ortotisyenler, fiziatristler gibi sağlık çalışanlarından olmuşlardır. Gözlemciliğini biomekanik bilgisine sahip ve hareket analizi üzerine bir kursu tamamlamış olan kinezyoloji öğrencilerinin yapığı bir çalışma ${ }^{16}$ dışında diğer tüm çalışmalarda gözlemciler, bir klinik geçmişe sahiplerdir. Bu çalışmalarının çoğunda gözlemcilere verilen eğitimden bahsedilememiştir. ${ }^{13,14,19,20}$ Gözlemcilerin geçmişiyle ilgili tek bahsedilen "tecrübeli gözlemciler" ${ }^{20 "}$ veya "sinyor terapistler" ${ }^{14 "}$ şeklinde yetersiz tanımlamalardır. Bazılarında ise hiç bahsedilmemiştir. ${ }^{19}$ Ancak son yapılan çalışmalarda gözlemcilerin hazırlanması konusuna önem verilmeye başlanmıştır. Bu konu üzerine en dikkatli yaklaşım kinezyoloji öğrencilerine verilen iki saatten ibaret bir eğitim seansını içeren Patla AE ve arkadaşlarının $1988^{\prime}$ de yaptığı çalışmadır. ${ }^{16}$ Bu eğitim seansında gözlemcilere normal yürümenin fazları, normal eklem hareket açıklığg gösterilerek her yürüme değişkeni tanımlanmıştır. Gözlemciler normal yürümeyi rahatça değerlendirebildiklerinde bir hastanın video görüntüleri gösterilmiştir. Gözlemciler anormallikleri belirlemek için bir uzman tarafından yönlendirilmişler ve yürümeyi istedikleri kadar izleme olanağına sahip olmuşlardır. Bir başka çalışmada yürüme değerlendirmesi üzerine beş yıldan fazla tecrübeye sahip olan üç fizyoterapist yeni bir GYA formu kullanmak için eğitilmiştir. ${ }^{10} \mathrm{Bu}$ çalışma için ortezle yürüyen ancak çalışmaya katılmayan üç çocuğun video görüntüleri gözlemcilere izletilmiştir. $\mathrm{Bu}$ eğitim üç gözlemcinin gösterilen yürüme deviasyonları için bir anlaşmaya varıncaya kadar devam etmiştir.

Eastlack ve arkadaşlarının çalışmasında ise yürüme değerlendirilmesi üzerine önceden tecrübe edinmiş veya edinmemiş 54 fizyoterapist; normal yürüme kinematiğine ait herhangi 
bir video gösterisinde bulunmadan sadece değerlendirme formunun nasıl kullanılacağının anlatımından ibaret bir eğitim seansı uygulamıştır. ${ }^{17}$

\section{Skorlama Metodu}

Yapılan sadece üç çalışmada gözlemcilerden yürüme deviasyonlarının nominal bir skalada değerlendirilmesi istenmiştir ${ }^{16,20}$, buna karşılık diğer tüm çalışmalarda yürüme deviasyonları üç nokta skalası ${ }^{10,13-14,17}$ veya dört nokta skalası ${ }^{19}$ veya 5 nokta skalas ${ }^{11}$ kullanılarak derecelendirilmiştir. Gözlemciler yürüme değişkenlerini; Kabul edilebilir, çoğalmaya ihtiyacı var, azalmaya ihtiyacı $\operatorname{var}^{14}$ veya yetersiz; normal, aşırı ya da yetersiz ${ }^{17}$; normal, sadece fark edilebilir ve oldukça fark edilebilir ${ }^{4,10}$; olarak değerlendirmişlerdir. Gerçekte yürüme deviyasyonlarının derecelendirilmesi oldukça önemli olmuştur ve Patla ve ark'ın belirttiği gibi, ordinal bir skalaya geçilmeden önce bir toplam skalası üzerinde güvenilirliğin gösterilmesi daha uygun olacağını belirtmişlerdir. ${ }^{16}$

\section{Verilerin Toplanması ve Veri Analizi}

Canlı yürümeye ait değerlendirme seansları hususunda tamamlanmamış bir bilgi birikimi mevcuttur. ${ }^{20}$ Videoya kaydedilmiş yürüme daha standardize haldedir. ${ }^{14,19,20}$ Yürünülen mesafe, adım sayısı, yürüme sayısı, çekim planları (lateral ve/veya frontal) ve kamera ile hasta arasındaki mesafe bile standardize edilmiştir. ${ }^{4,16,17}$ Eğer standardize edilmiş bir analiz metodu kullanılmak isteniyorsa değerlendirme prosedüründe bazı değişiklikler yapmak gerekmektedir. Videoya kaydedilmiş yürümeyi gözlemciler, bireysel olarak ${ }^{16}$, küçük bir grup halinde ${ }^{17}$ veya çalışmaya dahil edilenlerin tümü şeklinde ${ }^{10}$ değerlendirebilirler. Eğer yürüyüş, videoya kaydedilmemişse gözlemciler, eşit zaman perioduyla yürüyüşü bağımsız olarak değerlendirmişlerdir. ${ }^{14}$ Canlı olarak yürüyüşün değerlendirildiği diğer çalışmalarda gözlem seansının nasıl kontrol edildiğine ilişkin herhangi bir bilgi verilmemiştir. ${ }^{19,20}$ Bilinmelidir ki her hastanın tüm gözlemciler tarafından izlendiği, gözlemciler arası güvenilirlik çalışmalarında, özellikle ikiden fazla gözlemci varlığında canlı yürüyüş değerlendirilse dahi çalışma kolayca yorumlanamaz. Video kaydı ile yapılan değerlendirmede gözlemciler arası fikir ayrılığı oranı, zaman ve hasta performansı göz önüne alındığında daha düşük olduğu görülür.

Genel olarak yürüyüşe ait videoteypler bireysel olarak analiz edilmiştir ve bunların 5 defa $^{10,16}$ veya 2 defanın üstünde geri alınmasına izin verilmiştir. ${ }^{4,11,17}$ Gözlemcilerin gerçek zamana ait gözlemsel değerlendirmelerini kolaylaştırmak için bazen videoyu normal hızda seyretmeleri gerektiği söylenmiştir. ${ }^{10,16}$ Yapılan bir çalışmada durdurma ve yavaşlatma 
fonksiyonları da kullanılmıştır. ${ }^{17}$ Sonrada videonun hızı, araştırmacının kendisi tarafından kontrol edilmiştir. Çünkü 54 gözlemciden oluşan bir gözlemci popülasyonun ayrıldığı küçük gruplara uygulanan değerlendirme seanslarında, video gösterimi her grubu farklı yönde etkileyebilirdi.

İster canlı ister video bazlı değerlendirmede yürüme analizi için kullanılan parametrelerin gözlemciler için standardize edilmesi önemlidir. Video gösteriminden önce gözlemcileri yönlendiren bilgilerde oldukça önem taşır.

\section{9. İstatiksel Analiz}

GYA güvenilirlik çalışmalarında farklı istatiksel yaklaşımlar vardır. istatiksel seçim basit tutarlılık yüzdelerinden kappa korolasyonuna ve sınıflar arası koralasyona kadar değişmektedir. Bazı veriler için çeşitli istatiksel testler uygulanmıştır. Buna örnek olarak iki farklı model sınıflar arası koralasyonu, pearson koralsyonu, kappa korolasyonu ve uyuşum yüzdelerinin birlikte kullanıldığı Krebs ve ark'nın 1985 'de yaptığ 1 çalışma verilebilir. ${ }^{10}$ Patla ve ark. ${ }^{16}$ görülen/görülmeyen güvenilirliğin karşılaştırılması alarak tanımlanan yeni bir analiz metodu kullanmışlardır. Bu metot fazla sayıda normal skorla birbirleri ile uyumlu olmasına karşın, anormal yürüme değişkenlerinden kaynaklanan ve uyuşmayan anormal görülen skor artışını önlemektedir. Bu metot geleneksel noktadan noktaya güvenilirlik ile benzerdir. Ancak tüm verilerin kullanılması yerine, analiz görülen/görülmeyen anormal ölçümler olarak konsantre edilmektedir. Görülen/görülemeyen gözlemci içi güvenilirlik görülen güvenilirlik içindeki değişiklikle karıştırılmıştır.

\section{GYA Sistemlerinin Güvenilirlik ve Kriter Bağımlı Geçerliliği}

Gözlemciler arası güvenilirlik; yürüme analizi üzerine yapılan tüm güvenilirlik çalışmaları göz önüne alınırsa, en iyi koşullarda orta derecede güvenilirdir. Her ne popülasyonda çalışılırsa çalışılsın, hangi sistem seçilirse seçilsin veya hangi istatiksel test uygulanırsa uygulansın hiçbir yaklaşım daha iyi bir sonuç elde edememiştir. GYA sistemlerinin güvenilirliği ile ilgili olarak ilk raporda 10 paraplejik hastanın 17 yürüme deviasyonunu üç fizyoterapist tarafından değerlendirilmiş ve \% 60 - \% 93 arasında değişen bir tutarlılık yüzdesi elde edilmiştir (ortalama \% 82.3, standart deviasyon: \% 9.5). Sonraki bir çalışmada $^{10}$ üç fizyoterapist 15 bilateral KAFO giyen çocuğun yürüyüşünü değerlendirmiş ve uyuşum yüzdeleri video ile incelenmesine rağmen Goodkin ve Diller'in sonuçlarında daha düşük çıkmıştır. Vakaların \% 67.5'inde tam bir kararlılık durumu hakim olmasına karşın gözlemciler arası uyuşmazlık $\% \quad 30$ olarak bulunmuştur. 18 yürüme değişkenin 
güvenilirliğinin değerlendirilmesi için sınıflar arası koralasyonu kullanıldığında 3 faz içeren basma doneminin 6 deviasyonu için güvenilirliğin 0.40-0.49 arasında (ortalama 0.48) olduğu görülmüştür. Miyazaki ve ark'ın 48 hemiplejik hastada uyguladığı vizüel değerlendirmede ${ }^{19}$ sınıflar arası koralasyon değerleri ortalama 0.48 olmasına rağmen aynı işlem Pearson koralasyonu ile yapıldığında ortalama 0.43-0.60 arasında olduğu rapor edilmiştir.

Akalan ve ark çalışmasında; Gözlemciler 3 nokta skalası kullanarak yürüme analizi formunu doldurmuştur. Gözlemciler arasında \%63 oranında total fikir birliği (gözlemciler arası güvenilirlik), her gözlemcinin yaptıkları iki gözlem arasında ise \%82 fikir birliğinin olduğu tespit edilmiştir. Çalışmalarda düşük güvenilirlik seviyesi elde edilmesinin nedenleri; Gözlemcilerin spesifik bir eğitim almamaları, 4 nokta skalası kullanarak yürüyüşü değerlendirmeleri ve bazı yürüyüş anomalilerinin tanımı ve yorumu hakkında yanılgıya düşmeleri olabilir. ${ }^{4}$ Son yapılan çalışmalarda metodolojik zayıflık olmasına rağmen araştırmacılar vizüel derecelendirme ve değişken ayrımını öncelikle Pearson korolasyonu ile hesaplamışlardır.

Dikkatlice hazırlanmış ve analiz prosedürüne ve yürüme kayıtlarının standardizasyonuna önem verilmiş bir çalışmada GYA değerlendirilmesinde hafif-orta derecede güvenilirlik tespit edilmiştir. Daha kesin güvenilirlik hesabı ise Kappa korolasyon kullanılarak yapılmış ve 0.27 (kappa ortalama 0.11-0.52) gibi düşük bir değer bulunmuştur. ${ }^{10}$ $\mathrm{Bu}$ düşük güvenilirliği açıklayan bir çok nedenden ilki Kappa korolasyonunun sınıflar arası koralasyondan daha düşük bir güvenilirlik değeri verdiğinin bilinmesidir. Örneğin aynı veriler için sınıflar arası koralasyonu ve Kappa korolasyonu uygulandığında, sınıflar arası koralasyon değeri (ort; 0.34) Kappa 'dan (ort; 0.27) daha yüksek olduğu gözlenmiş ve sınıflar arası koralasyonunun güvenilirlik seviyesi üzerine daha yoğun bir hesaplama yeteneği olduğu anlaşılmıştır. İkinci olarak ellidört hastanın randomize edilmemiş video kayıtları ile oluşan ön yargıyla birlikte eğitim eksikliği, üç romotoid artritli hastanın yürüyüşünü değerlendirirken gözlemci uyuşumunu oldukça etkilemiştir. Akalan ve arkadaşlarının ise oldukça Standard yöntemlerle yaptıkları güvenilirlik çalışmasında, Kappa karşılaştırma sonuçları orta-ileri seviyede gözlemciler arası güvenilirlik ve ileri düzeyde gözlemci içi güvenilirliğin olduğunu ortaya koymuştur. $^{4}$

Heteraojen örnekli tek çalışmada (farklı tür hastalığı ve sakatlığı bulunanlar) GYA sonucu orta derecede bir güvenilirlik seviyesine ulaşılmıştır. ${ }^{16}$ Görülebilen/görülemeyen türünde bir korolasyon kulanıldığında maximum 10 skorun 4-5'inde uyuşum saptanmıştır. Gözlemciler 2 saatlik bir eğitim almaları (normal yürüyüş dahil) ve nominal bir skala kullanmalarına rağmen, klinik tecrübeleri bulunmayan kinezyoloji öğrencilerinden oluşan 
gözlemci topluluğundan oluşmaları, patolojik yürümeyi değerlendirmekte güçlük çekmelerine neden olmuştur. $\mathrm{Bu}$ klinik tecrübe eksikliği ve değişik hastalığa sahip her hastalığın değerlendirilmesindeki zorluk, düşük düzeydeki tutarlılığa katkıda bulunmuş olabilir. Bruin ve ark'ın çalışmasında ise alınan sonucu yorumlamak oldukça zor olmuştur çünkü saptanan yegane sonuç gözlemciler arası güvenilirliğin çok değişken olduğu olmuştur. ${ }^{13}$

Yapılan çalışmalardan bazıları diğerlerine göre daha güvenilir sonuçlar bulmuşlardır. $\mathrm{Bu}$ çalışmalarda basma döneminin salınım dönemine göre daha değişken olduğu gösterilmiştir. ${ }^{10,16}$ Ayrıca sagital plan frontal plana göre daha yüksek güvenilirliğe sahip olduğu anlaşılmıştır. ${ }^{10,14,17}$ Zaman ve mesafe ile ilgili az sayıda araştırma vardır. Bundan başka zaman-mesafe değişkenleri hastaların yürüdüğü yürüme yoluna horizontal yerleşimli işaretlerle nitel veriler olarak ölçülebilirdi. (Basma zamanı, adım uzunluğu, birim zamanda atılan adım sayısı vs.) Ayrıca kare-kare analiz (zaman tespiti için) ve yer işaretleri (mesafe tespiti için) ile gözlemciler daha kolay değerlendirme yapabilirdi. ${ }^{4}$

\section{Gözlemci İçi Güvenilirlik,}

Gözlemci içi güvenilirliği değerlendiren sadece üç çalışma vardır.,10,11 $\mathrm{Bu}$ çalışmalarda total gözlemci içi uyuşumun ortalama yüzdesi gözlemciler arası güvenilirliğe göre biraz daha yüksek bulunmuştur. Gözlemciler arası güvenilirliğe göre pearson korolasyonun ortalaması orta-ileri düzeyde olduğu gözlenmiştir. Gözlemci içi ve gözlemciler arası güvenilirlik arasındaki asıl fark, gözlemciler arasında horizontal ve frontal plan değerlendirme tutarlılığının gözlemci içinden daha düşük seviyede olmasıdır. Gözlemci içi güvenilirlik hakkında yapılan bir diğer araştırmada gözlemci içi değişkenlik \% 30 olarak bulunmuştur. ${ }^{13}$

\section{Kritere Bağımlı Geçerlilik}

Yapılan GYA çalışmaları karşılaştırıldığında eklem hareketinin, ilerleticili video analiz yöntemi ile değerlendirilmesi, yürüme deviasyonlarının saptanma kapasitesi yükseltilebildiği sonucu çıkmaktadır. ${ }^{16}$ Ancak diz ve kalça eklemlerindeki yürüme deviyasyonlarının saptanma kapasiteleri düşüktür. Gözlemcilerin, patolojiler üzerine önyargılı yaklaşmaları bu konuda muhtemel bir sebep oluşturabilir. Örneğin kalça artroplastisi geçiren bir hastanın güvenilirlik skoru yüksek, buna karşın geçerliliği düşük bulunmuştur. Gözlemciler patolojiye ait değişkenleri bir önyargıyla anormal olarak değerlendirmiş ve nicel veri ölçümleri onları yanılgıya düşürmüş olabilir. Eğer gözlemcilerin yürüme anormalliklerini saptama kapasitesini enstrümental ve biomekaniksel analize göre beklenen deviasyonlar ile 
karşılaştırarak ölçmek istersek alınan sonuç \% 22 den az olabilir. ${ }^{20}$ Ancak mesafe ve zaman değişkenlerini arka plana atarsak kapasite \% 66.4'e çıkar. \% 92.5'inde devaisyon varolan bir populasyonda yürüme deviyasyonlarının gözlemsel olarak saptanması için önerilen; belirli bir eşik değeri üzerindeki yürme deviyasyonların gözlemsel olarak algılanabileceği yönündedir. Sorun, bu eşiğin duyarlılığını belirleyebilmektir. Bu yüzden şimdiye kadar yapılan çalışmaların sonuçları yalancı pozitif olarak yorumlanabilir. Vizüel skorlar ile yer reaksiyon kuvvetini ölçerek elde edilen zeman-mesafe verileri arasında bir dalga formu oluşturan pearson korolasyon ölçümü, doğruluğu az olan bir skorlama metodudur. ${ }^{19}$ Çünkü ortalama pearson korolasyon değerleri bu çalışmaya katılmayan temporal değerler için daha yüksektir(r $=0.42$ yerine 0.52 ).

Tüm güvenilirlik çalışmalarından elde edilen sonuç, GYA'nın güvenilirliğinin arttırılmasının zorunluluğudur. Potansiyel güvenilirlik arttırıcı faktörler olarak, gözlemci eğitiminin standardizasyonu, normalin daha iyi bilinmesi, iyi geliştirilmiş optimal tanımlar ve basit skorlama sistemlerinin kullanılması verilmiştir. Veri kolleksiyonunun standardizasyonu gözlemsel yöntemin güvenilirliğini arttırabilir. Geçerlilik çalışmalarının sonucu ise pek açık değildir. Geçerlilik çalışmaları yürüme deviasyonlarının gözlemsel olarak değerlendirilmesi sırasında eşiğin tespiti için yapılmışlardır. Eğer verilen görevler makul olursa gözlemciler oldukça güvenilir olabilirler. ${ }^{18} \mathrm{Bu}$ yüzden yüksek güvenilirlikli GYA sistemlerinin geliştirilmesi ve bu sistemlerin objektif ve kliniksel bir yürüme değerlendirme aracı olarak kullanılması mümkün gözükmektedir. ${ }^{18}$

Özet olarak iki katagoride yürüyüş değerlendirme sistemi tanımlanmıştır. Ambulasyon profilleri ve GYA metodları, ambulasyon profilleri, fonksiyonel skorları ve zaman-mesafe ölçen nitel metodlardır ve böylece ayakta durma dengesinden bağımsız yürümeye kadar çeşitli kabiliyetleri değerlendirir. GYA ise yine zaman-mesafe değişkenlerini ve eklem açıklığına ait yürüme deviasyonlarını gözlemsel olarak değerlendirir. Zamanmesafe ölçümleri objektif verilerle yapılırsa yüksek bir tekrarlanabilirlik kapasitesine sahipken (ambulasyon profilleri), gözlemsel metot ile yapıldığında oldukça tutarsız hale gelmektedir. Bu sonuçlar gözlemcinin zaman-mesafe değişkenlerini daha nitel yaklaşımlarla değerlendirmesi gerektiğini göstermiştir. Bu derleme, günümüzde GYA' güvenilirliğinin; orta seviyede gözlemciler arası güvenilirlik ve ileri düzeyde gözlemci içi güvenilirliğin olduğunu ortaya koymuştur. Sonuç olarak gözlemci içi güvenilirlik VBGYA’nin klinkte kullanılabileceğini, ancak gözlemciler arası güvenilirliğin yükseltilmesi için çalışılması gerektiği ortaya konmuştur. Genel olarak bakıldığında GYA'nın güvenilirliğinin arttırılması için, çok açık şekilde tanımlanmış parametrelerin, standart bir çekim metodu ile video 
kayıtları alındıktan sonra, konuyla ilgili 3 yılı aşkın tecrübesi olan ve inceleme hakkında kısa standart bir eğitimden geçen gözlemciler tarafindan, sadece basma fazı için incelenmesinin gerektiği ortaya çıkmaktadır.

\section{Kaynaklar}

1. Silva M, Shepherd EF, Jackson WO, Dorey FJ, Schmalzried TP. [Average patient walking activity approaches 2 million cycles per year: pedometers under-record walking activity]. J. Arthroplasty. 2002; 17(6):693-7.

2. Sequeira MM, Rickenbach M, Wietlisbach V, Tullen B, Schutz Y. [Physical activity assessment using a pedometer and its comparison with a questionnaire in a large population survey]. Am J Epidemiol. 1995;142(9):989-99.

3. Perry, J. Fundimentals In: Gait Analysis: Normal and Pathological Function, 1.ed. New York; SLACK Incorporated, 1992, p. 1-19.

4. Akalan N.E. 1999. Serebral parezili çocuklarda video bazlı gözlemsel yürüme analizinin gözlemci içi ve gözlemciler arası güvenilirliğinin belirlenmesi · Istanbul Universitesi, Sağlık Bilimleri Ens. Yüksek lisans Tezi. 79773.

5. Maluin F: Observational Gait Analysis. In: Rebecca L. Craik, Carol A. Oatis, Gait Analysis, Theory and Application, 1.ed, Pennsylvania, Mosby, 1995. p.113-123.

6. Reimers J. [A scoring system for the evaluation of ambulation in cerebral palsied patients]. Dev Med Child Neurol. 1972;14(3):332-5.

7. Nelson AJ.[ Functional ambulation profile]. Phys Ther. 1974;54(10):1059-65.

8. Olney SJ, Write MJ: Cerebral Palsy. In Campbell S K, Linden DWV, Palsido RJP: Physical Therapy For Children. Londra, 2. ed. W.B. Sounders Company, 1995: p.489-525.

9. Wolfson L, Whipple, Amerman P.Tobin J.N. [Gait assessment in the Elderely: A gait abnormality rating scale and its relation to falls], Journal of Gerontology: Medical Sciences 1990; 45(1): 12-19.

10. Krebs D. E. Edelstein J.E, Fishman S. [Reliability of observational gait analysis]. Physical Therapy, 1985; 65(7): 1027-33.

11. Maathuis KG, van der Schans CP, van Iperen A, Rietman HS, Geertzen JH. [Gait in children with cerebral palsy: observer reliability of Physician Rating Scale and Edinburgh Visual Gait Analysis Interval Testing scale]. J Pediatr Orthop. 2005; 25(3):268-72.

12. Caroll NC, Jones D, Maschuich W. [Evaluations patients to the gait children with miyelomeningocele]. Prostet. Orthot. Int.1982; 6:27-34. 
13. de Bruin H, Russell DJ, Latter JE, Sadler JT.[Angle-angle diagrams in monitoring and quantification of gait patterns for children with cerebral palsy]. Am J Phys Med. 1982;61(4):176-92.

14. Goodkin R Diller L. [Reliability among physical therapistsin diagnosis and treatment of gait deviationin hemiplegics]. Perceptual and Motor Skills, 1991; 37:727-734.

15. Robinson JL, Smidth GL. [Quantitative gait evaluation in clinic]. Physical Therapy 1981;61: 351-353.

16. Patla AE, Clouse SD. [Visuel assessent of human gait: Reliability and validity]. Rehabil. Res. 1988; 1:87-96.

17. Eastlack ME, Arvidson J, Snyder-Mackler L, Danoff JV, McGarvey CL. [Interrater reliability of videotaped observational gait analysis]. Physical Therapy, 1991;71: 465-472.

18. Winter DA. [Concerning the scientific basis for the diagnosis of pathological gait and for rehabilitation protocols], Physiotherapy Canada, 1985; 37(4): 245-252.

19. Miyazaki S. Kubotta T. [Quantification of gait abnormalities, on the basis of continuous foot- force measurement: correlation between quantitative indices and visual rating]. Med Biol. Eng. Comput 1984; 22:70-76.

20. Saleh M, Murdoch G. [In defence of gait analysis: Observation and measurement in gait assessment]. The Journal of Bone and Joint Surgery.1985; 67(2):237-4. 